\title{
Análise da heterose de cruzamentos entre variedades de arroz-vermelho
}

\author{
José Almeida Pereira(1), Orlando Peixoto de Morais ${ }^{(2)}$ e Flávio Breseghello(2) \\ (1)Embrapa Meio-Norte, Caixa Postal 1, CEP 64006-220 Teresina, PI. E-mail: almeida@cpamn.embrapa.br (2)Embrapa Arroz e Feijão, Caixa \\ Postal 179, CEP 75375-000 Santo Antônio de Goiás, GO. E-mail: peixoto@cnpaf.embrapa.br, flavio@cnpaf.embrapa.br
}

\begin{abstract}
Resumo - O objetivo deste trabalho foi avaliar, por meio de análise dialélica, o potencial de dez variedades de arroz-vermelho para a implementação de um programa de melhoramento. A identificação de genitores foi feita com dez variedades, em um cruzamento dialélico completo sem recíprocos. As variedades e seus 45 cruzamentos foram avaliados nas gerações $F_{1}$ e $F_{3}$, quanto às suas características agronômicas, em delineamento em blocos ao acaso. Para o caráter produção de grãos, foram avaliados: a heterose do cruzamento $(\mathrm{H})$, o efeito varietal (v), a heterose média $(\overline{\mathrm{h}})$, a heterose varietal $(\mathrm{h})$ e a heterose específica (s) em cada geração, além da capacidade geral de combinação $(\mathrm{g})$ dos genitores. Foram detectadas diferenças significativas entre as variedades genitoras, quanto às características agronômicas avaliadas, e foram considerados mais promissores, para a seleção de novas linhagens, os cruzamentos 'AL03/PB13' e 'PB05/PB10', em razão das estimativas favoráveis dos parâmetros relacionados à produtividade, à diversidade genética e à capacidade de combinação de seus genitores.
\end{abstract}

Termos para indexação: Oryza sativa, arroz-da-terra, capacidade de combinação, melhoramento de arroz, vigor híbrido.

\section{Heterosis analysis in crosses among red rice varieties}

\begin{abstract}
The objective of this work was to evaluate, using the diallelic analysis, the potential of ten varieties of red rice for the implementation of a breeding program. The identification of parents was performed with ten lendraces was performed with in a complete diallel crossing without reciprocals. The varieties and their 45 diallel crosses were evaluated in generations $\mathrm{F}_{1}$ and $\mathrm{F}_{3}$ for agronomic traits in a randomized block design. For the yield character, the following characteristics were evaluated: varietal effect, varietal heterosis and specific heterosis in each generation, plus the general combining ability. Significant differences among parents for the traits evaluated were detected; and the crosses 'AL03/PB13' and 'PB05/PB10' were considered the most promising for selection of elite lines of red rice for the favorable parameter estimates related to yield, genetic diversity and combining ability of their parents.
\end{abstract}

Index terms: Oryza sativa, country rice, combining ability, rice breeding, hybrid vigor.

\section{Introdução}

Em todo o mundo predomina a produção e o consumo do arroz-branco, oriundo de variedades da espécie Oryza sativa L. A cor característica do pericarpo do grão dessa espécie é a vermelha, herdada do seu ancestral silvestre Oryza rufipogon. A cor branca, predominante entre as variedades plantadas, originou-se de mutação e tornou-se uma característica de interesse comercial e prioritária nos processos de seleção da maioria dos programas de melhoramento genético do arroz (Pereira et al., 2007).

A cor do pericarpo do arroz é uma característica controlada pelo gene $R d$, no cromossomo 1, e pelo gene $R c$ no cromossomo 7. O genótipo $\mathrm{Rd} / \mathrm{Rc}$ dá origem a grãos com o pericarpo vermelho; o genótipo $\mathrm{rd} / \mathrm{Rc}$ produz grãos com o pericarpo marrom, enquanto as combinações alélicas $\mathrm{Rd} / \mathrm{rc}$ ou $\mathrm{rd} / \mathrm{rc}$ resultam em grãos com pericarpo branco (Sweeney et al., 2006).

O pigmento vermelho do grão do arroz é uma proantocianina de grande valor para a alimentação humana. Esse pigmento é responsável pela alta digestibilidade e pela ação antioxidante, capaz de reduzir a formação de placas ateroscleróticas, um fator de risco associado a doenças cardiovasculares, e ainda atua como importante repelente a alguns patógenos e predadores da cultura do arroz (Sweeney et al., 2006).

Por suas características diferenciadas em relação ao arroz-branco como sabor, textura e provável valor medicinal, o arroz-vermelho é cultivado em algumas 
regiões do Brasil, Argentina, Nicarágua, Venezuela, França, Rússia, Madagascar, Moçambique, Filipinas, Malásia, Sri Lanka, Índia, China, Nepal, Butão, Indonésia, Tailândia, Japão e Coréia do Sul, entre outros países.

$\mathrm{O}$ arroz-vermelho foi introduzido no Brasil pelos portugueses, no século XVI, e ficou conhecido como arroz-vermelho ou por outros nomes como arroz-daterra e arroz-de-veneza. Atualmente, seu cultivo no Brasil está restrito a pequenas áreas do Semi-Árido nordestino, onde figuram, pela ordem decrescente de importância da cultura, os estados da Paraíba, Rio Grande do Norte, Pernambuco, Ceará, Bahia e Alagoas. Variedades tradicionais vermelhas também são plantadas em alguns municípios do Norte de Minas Gerais (Pereira, 2002, 2004).

As variedades existentes, em geral, apresentam arquitetura de planta tradicional (porte alto, folhas longas, largas e decumbentes), alta suscetibilidade ao acamamento e baixo potencial genético de produção. Contudo, ainda que não seja comum, existem variedades com arquitetura de planta moderna (porte baixo, folhas curtas, estreitas e eretas), baixo índice de acamamento e elevado potencial produtivo. Algumas dessas variedades poderiam ser úteis em um programa de melhoramento genético, para a obtenção de cultivares de arroz-vermelho (Pereira, 2004; Pereira et al., 2007). O arroz-vermelho, portanto, representa um valioso patrimônio genético, alimentar e cultural da região do Semi-Árido nordestino, que só recentemente começou a ser estudado.

Uma pequena coleção de variedades tradicionais foi estabelecida pela Empresa Brasileira de Pesquisa Agropecuária (Embrapa). Como resultado dos trabalhos de caracterização de amostras dessa coleção, algumas variedades já foram identificadas como potencialmente úteis para o melhoramento genético do arroz-vermelho, para a redução da altura de planta, do acamamento e o aumento da produtividade de grãos, além de outras características de importância agronômica (Areias et al., 2006; Passos et al., 2007). Uma informação importante para a orientação de ações de melhoramento genético refere-se ao grau de divergência e à capacidade de combinação genética das variedades mais produtivas (Kurek et al., 2001; Rodrigues et al., 2002). A análise de cruzamentos dialélicos é uma abordagem da genética quantitativa que pode fornecer essas informações (Silva et al., 2000; Veiga et al., 2000; Gravois \& McNew, 2003).
O objetivo deste trabalho foi avaliar, por meio de análise dialélica, o potencial de dez variedades de arroz-vermelho, para fins de melhoramento genético.

\section{Material e Métodos}

Realizou-se um dialelo completo, sem os recíprocos, tendo-se utilizado dez variedades de arroz-vermelho, selecionadas entre os materiais atualmente plantados na região Nordeste do Brasil, das quais três provenientes do Estado de Alagoas ('AL01', 'AL03' e 'AL04') e sete do Estado da Paraíba ('PB04', 'PB05', 'PB09', 'PB10', 'PB11', 'PB12' e 'PB13'). Os cruzamentos foram realizados na Embrapa Arroz e Feijão e as avaliações das gerações $F_{1}$ e $F_{3}$ foram efetuadas na Embrapa Meio-Norte, em Teresina, PI (à altitude de $70 \mathrm{~m} \mathrm{e}$ $5^{\circ} 5$ 'S, $\left.42^{\circ} 49^{\prime} \mathrm{W}\right)$.

As avaliações das duas gerações foram realizadas separadamente no tempo, tendo-se mantido os dez genitores e uma variedade adicional, PB01, como tratamentos comuns. Essa variedade, também tradicionalmente cultivada na região, foi incluída para conferir maior precisão no ajuste das médias das duas gerações, para efeito de ano, em razão dos tratamentos comuns. A geração $F_{1}$ foi avaliada no segundo semestre de 2005, em regime de irrigação por inundação com lâmina de água controlada, em delineamento experimental de blocos completos ao acaso, com três repetições. Cada parcela constituiu-se de uma linha com 12 mudas transplantadas, com espaçamento de $0,25 \mathrm{~m}$ entre plantas e $0,30 \mathrm{~m}$ entre linhas, em que a área útil da parcela foi constituída pelas dez plantas centrais da linha $\left(0,75 \mathrm{~m}^{2}\right)$.

Durante o período chuvoso, no primeiro semestre de 2006, procedeu-se ao avanço de geração dos cruzamentos, em condições de sequeiro. As 45 populações $F_{3}$, e novamente os dez genitores e a 'PB01', foram avaliados no segundo semestre de 2006, com delineamento, manejo e espaçamento similares aos utilizados na avaliação da geração $F_{1}$. Na geração $F_{3}$, porém, utilizou-se a semeadura direta, e as parcelas foram constituídas de três linhas de $5 \mathrm{~m}$, espaçadas de $0,30 \mathrm{~m}$, à densidade de 20 sementes por metro linear. As características altura de planta e produtividade de grãos foram avaliadas nos dois ensaios. No primeiro ensaio, foram avaliados, ainda: número de panículas por planta, número de espiguetas por panícula e peso de 100 grãos, e no segundo ensaio, o número de dias para a floração média. 
No segundo ensaio, 22 parcelas, dispersas pelos três blocos, foram prejudicadas pelo ataque de roedores, e seus dados foram eliminados da análise estatística, para se evitar o aumento do erro experimental. Nenhum tratamento, contudo, ficou desprovido de informação. As pressuposições básicas para a análise de variância (Zimmermann, 2004) foram obedecidas em relação a todas as características. As médias dos genitores e dos cruzamentos, nas duas gerações, ajustadas para efeito de ano de avaliação e de repetição dentro de ano, foram estimadas pela análise conjunta dos dois experimentos pelo PROC GLM (SAS Institute, 1993). A interação tratamentos $\mathrm{x}$ anos foi considerada componente do erro experimental, condição necessária para a estimabilidade das médias ajustadas dos tratamentos (Searle, 1971).

Para cada geração, estimou-se o valor da heterose (H) pelo contraste entre a média ajustada do cruzamento e de seus genitores (Viana, 2000, 2007). A variância de cada estimativa de $\mathrm{H}$ foi calculada, tendo-se considerado as variâncias e covariâncias das médias de genitores e cruzamentos envolvidos, presentes na matriz de variância das médias ajustadas.

A análise da heterose foi realizada pela metodologia de Gardner \& Heberhart (1966), com a adaptação necessária para os dados desbalanceados e não ortogonais, analogamente ao realizado por Silva et al. (2000) para a metodologia de Griffing (1956). Por meio dessa análise, obtiveram-se também estimativas do efeito varietal (v) de cada genitor e de capacidade geral de combinação $(\mathrm{g})$.

Para a estimação dos efeitos de variedades e dos componentes de heterose foi adotado, para a geração $\mathrm{k}, \mathrm{o}$ seguinte modelo estatístico:

$\mathrm{Y}_{\mathrm{kij}}=\mu+\frac{\left(\mathrm{v}_{\mathrm{i}}+\mathrm{v}_{\mathrm{j}}\right)}{2}+\theta\left(\overline{\mathrm{h}}_{\mathrm{k}}+\mathrm{h}_{\mathrm{ki}}+\mathrm{h}_{\mathrm{kj}}+\mathrm{s}_{\mathrm{kij}}\right)+\varepsilon_{\mathrm{kij}}$, em que: $\mathrm{Y}_{\mathrm{kij}}$ é a média estimada do cruzamento entre as variedades i e j, na geração $F_{k} ; \mu$ é a média geral; $v_{i}$ e $v_{j}$ são os efeitos das variedades $i \mathrm{e} j$, respectivamente; $\theta$ é a variável indicadora. $\theta=0$ se $\mathrm{i}=\mathrm{j}$, caso contrário, $\theta=1 ; \bar{h}_{k}$ é a heterose média na geração $F_{k} ; h_{k i}$ e $\mathrm{h}_{\mathrm{kj}}$ representam a heterose atribuída à variedade $\mathrm{i}$ ou $\mathrm{j}$, respectivamente, na geração $\mathrm{F}_{\mathrm{k}} ; \mathrm{s}_{\mathrm{kij}}$ é a heterose específica do cruzamento entre as variedades $\mathrm{i}$ e $\mathrm{j}$ na geração $\mathrm{F}_{\mathrm{k}} ; \varepsilon_{\mathrm{kij}}$ é o erro experimental associado à média $Y_{\text {kij }}$ (não homogêneos e não ortogonais).

Na diagonalização por congruência da matriz $\mathrm{V}^{-1}$, inverso da matriz de co-variância das médias ajustadas das variedades genitoras e de seus cruzamentos nas $\mathrm{k}$ gerações, foi utilizado o aplicativo R (www.r-project.org). Com essa operação, obtém-se a matriz congruente $F$, tal que $\mathrm{FF}^{\prime}=\mathrm{V}^{-1}$, empregada na simplificação do modelo linear generalizado de Gauss-Markov (Searle, 1971), e utilizada por Silva et al. (2000) na proposição de seu procedimento generalizado de análise de dialelos desbalanceados. Todas as demais operações matriciais, necessárias à estimação dos parâmetros do modelo e de seus erros associados, foram realizadas com o aplicativo BrOffice.org Calc (www.broffice.org). A matriz de restrições foi estruturada, tendose admitido os seguintes cortes no espaço das soluções:

$\sum_{\mathrm{j}} \hat{\mathrm{v}}_{\mathrm{j}}=0 ; \sum_{\mathrm{j}} \hat{\mathrm{h}}_{\mathrm{kj}}=0$, para cada $\mathrm{k} ; \sum_{\mathrm{j}} \hat{\mathrm{s}}_{\mathrm{kij}}=0, \quad$ para cada i e k.

Para realizar uma decomposição, necessariamente não ortogonal nesse caso, da soma de quadrados (SQ) de tratamentos, ajustada em SQ(v), SQ( $\left.\mathrm{H}_{\mathrm{k}}\right), \mathrm{SQ}\left(\overline{\mathrm{h}}_{\mathrm{k}}\right)$, $\mathrm{SQ}\left(\mathrm{h}_{\mathrm{ki}}\right), \mathrm{SQ}\left(\mathrm{s}_{\mathrm{kij}}\right)$, para cada $\mathrm{k}$, utilizou-se a seguinte expressão, adaptada da equação geral da soma de quadrados de hipótese em modelos lineares (Searle, 1971), para cada componente de variação:

$\mathrm{SQ}=(\mathrm{C} \beta)^{\prime}(\mathrm{CWC})^{-1}(\mathrm{C} \beta)$,

em que: $C$ é uma matriz de contrastes das estimativas dos efeitos de cada componente de variação; $\beta$ é o vetor de soluções da equação do dialelo; W é a matriz de co-variância de $\beta$, obtida conforme Silva et al. (2000), dividida pelo quadrado médio do resíduo da análise de variância conjunta dos experimentos.

Para a soma de quadrados relativa à heterose média, com um grau de liberdade, a linha da matriz $\mathrm{C}$ deve ser estabelecida de tal forma a reproduzir a expressão:

$\overline{\mathrm{h}_{\mathrm{k}}}-\frac{1}{\mathrm{p}} \sum_{\mathrm{i}=1}^{\mathrm{p}} \hat{\mathrm{h}}_{\mathrm{ki}}=0$,

em que $\mathrm{p}$ corresponde ao número de variedades genitoras.

Segundo Oliveira et al. (2004) e Viana (2007), a capacidade geral de combinação da variedade genitora $\mathrm{i}\left(\mathrm{g}_{\mathrm{i}}\right)$ pode ser estimada a partir do modelo de Gardner $\&$ Heberhart (1966), por $\mathrm{g}_{\mathrm{i}}=\mathrm{V}_{\mathrm{i}} / 2+\mathrm{hi}_{\mathrm{i}}$.

Neste trabalho, que aborda de forma conjunta as gerações $F_{1}$ e $F_{3}$, a estimação de $g$ foi feita pela expressão: 
$\hat{\mathrm{g}}_{\mathrm{i}}=\frac{\hat{\mathrm{v}}_{\mathrm{i}}}{2}+\frac{1}{\mathrm{n}} \sum_{\mathrm{i}=1}^{\mathrm{p}} \hat{\mathrm{h}}_{\mathrm{ki}}$

para $\mathrm{k}=1$ e 3 , sendo $\mathrm{n}=2$ (número de gerações envolvidas).

\section{Resultados e Discussão}

As estimativas das médias de número das características avaliadas, relativas aos genitores e à variedade PB01 estão listadas na Tabela 1. Sete das dez variedades utilizadas como genitoras e a 'PB01' constituem um grupo mais precoce, que apresenta floração média dos 67 aos 72 dias após a emergência das plântulas. A 'PB11' é a mais tardia, com floração média aos 93 dias, enquanto a 'AL03' e a 'PB05' têm duração de ciclo intermediário, floração média aos 81 e 85 dias após a semeadura, em Teresina, PI (Tabela 1). As variedades de arroz mais tardias tendem a ser mais produtivas (Pinheiro, 2006), no entanto, no presente trabalho, não se observou nenhuma correlação entre número de dias quanto ao florescimento e à produtividade de grãos $(\mathrm{r}=0,01)$.

As variedades genitoras são também altamente contrastantes quanto à altura de planta, medida do solo até a extremidade da panícula. Este caráter variou de 99,3 cm, na 'PB09', até $159 \mathrm{~cm}$, na 'AL04'. Foram observadas, ainda, variações significativas entre as variedades parentais, no que tange ao número de panículas por planta, número de espiguetas por panícula e massa de 100 grãos. A variedade PB12 apresentou baixo número de panículas por planta e de espiguetas por panícula, o que resultou em baixa produtividade, apesar de sua elevada massa de 100 grãos.
Duas variedades destacaram-se quanto à produção de grãos: AL03 e PB13. Suas médias de produtividade são superiores às das quatro variedades menos produtivas (PB12,AL01, PB04 e PB11). As outras cinco variedades (quatro genitoras e a PB01) comportaram-se como intermediárias no que tange à produtividade, sem diferenças estatísticas em relação aos componentes dos dois primeiros grupos, exceto a 'PB05', que se revelou mais produtiva que a 'PB12' do segundo grupo.

O coeficiente de variação experimental (CV), relativo à produção de grãos da análise conjunta, foi de $22,4 \%$. Possivelmente, ter-se-ia um menor $\mathrm{CV}$, com a utilização de outro delineamento experimental, que permitisse a alocação de menor número de tratamentos por bloco experimental. No presente caso, havia 56 tratamentos por bloco experimental, número relativamente alto para delineamento em blocos completos ao acaso (BCA). Zimmermann (2004) informa que não há limites no número máximo de tratamentos para esse delineamento, mas que é conseqüência do tamanho de cada unidade experimental, da definição física de blocos e da amplitude do ambiente homogêneo em que é alocado cada bloco. Em experimentos de arroz irrigado, com parcelas de seis linhas de $5 \mathrm{~m}$, espaçadas em $20 \mathrm{~cm}$, por exemplo, tem-se normalmente utilizado até 25 tratamentos, eventualmente um pouco mais, quando se emprega BCA. Naturalmente, com um menor número de tratamentos, a probabilidade de se ter uniformidade ambiental dentro do bloco é aumentada o que reduz os erros experimentais.

Costa et al. (2002) trabalharam com arroz de terras altas e consideraram como medianos os valores de $\mathrm{CV}$ entre 13,2 e $43,7 \%$, para experimentos com 30 a 100 tratamentos, em delineamento BCA, enquanto em

Tabela 1. Médias de características fenológicas e agronômicas das dez variedades genitoras e da variedade PB01 ${ }^{(1)}$.

\begin{tabular}{|c|c|c|c|c|c|c|}
\hline Genitor & $\begin{array}{c}\text { Ciclo até a } \\
\text { floração (dia) }\end{array}$ & $\begin{array}{c}\text { Altura de } \\
\text { planta }(\mathrm{cm})\end{array}$ & $\begin{array}{l}\text { Panículas/ } \\
\text { planta }\end{array}$ & $\begin{array}{l}\text { Espiguetas/ } \\
\text { panícula }\end{array}$ & $\begin{array}{c}\text { Massa de } \\
100 \text { grãos }(\mathrm{g})\end{array}$ & $\begin{array}{c}\text { Produção } \\
\left(\mathrm{g} \mathrm{m}^{-2}\right)\end{array}$ \\
\hline AL01 & $67,7 \mathrm{c}$ & $135,8 \mathrm{~b}$ & $13,0 \mathrm{ab}$ & $121,0 \mathrm{ab}$ & $2,58 \mathrm{bc}$ & $670,5 b c$ \\
\hline AL03 & $81,0 \mathrm{~b}$ & $139,0 \mathrm{ab}$ & $19,0 \mathrm{ab}$ & $93,3 \mathrm{ab}$ & $3,11 \mathrm{ab}$ & $935,7 \mathrm{a}$ \\
\hline AL04 & $70,7 \mathrm{c}$ & $159,0 \mathrm{a}$ & $15,7 \mathrm{ab}$ & $124,7 \mathrm{ab}$ & $3,22 \mathrm{a}$ & $796,2 \mathrm{abc}$ \\
\hline PB04 & $70,7 \mathrm{c}$ & $102,2 \mathrm{c}$ & $14,3 \mathrm{ab}$ & $136,3 \mathrm{a}$ & $2,71 \mathrm{abc}$ & $686,7 \mathrm{bc}$ \\
\hline PB05 & $85,0 \mathrm{~b}$ & $112,5 \mathrm{c}$ & $17,3 a b$ & $136,7 \mathrm{a}$ & $2,29 \mathrm{c}$ & $843,9 a b$ \\
\hline PB09 & $71,7 \mathrm{c}$ & $99,3 \mathrm{c}$ & $16,7 \mathrm{ab}$ & $106,3 \mathrm{ab}$ & $2,72 \mathrm{abc}$ & $731,8 \mathrm{abc}$ \\
\hline PB10 & $67,7 \mathrm{c}$ & $101,3 \mathrm{c}$ & $14,3 \mathrm{ab}$ & $96,0 \mathrm{ab}$ & $2,69 \mathrm{abc}$ & $763,4 \mathrm{abc}$ \\
\hline PB11 & $93,3 a$ & $107,2 \mathrm{c}$ & $18,3 \mathrm{ab}$ & $102,3 \mathrm{ab}$ & $2,75 \mathrm{abc}$ & $693,4 b c$ \\
\hline PB12 & $71,7 \mathrm{c}$ & $121,5 \mathrm{bc}$ & $10,0 \mathrm{~b}$ & $76,7 \mathrm{~b}$ & $3,16 \mathrm{ab}$ & $600,0 \mathrm{c}$ \\
\hline PB13 & $69,3 c$ & $112,0 \mathrm{c}$ & $21,0 \mathrm{a}$ & $107,7 \mathrm{ab}$ & $2,85 \mathrm{abc}$ & $930,7 \mathrm{a}$ \\
\hline $\mathrm{PB} 1^{(2)}$ & $67,3 \mathrm{c}$ & $137,2 \mathrm{ab}$ & $17,0 \mathrm{ab}$ & $107,0 \mathrm{ab}$ & $3,15 \mathrm{ab}$ & $778,5 \mathrm{abc}$ \\
\hline Média dos ensaios & 69,4 & 122,7 & 17,8 & 107,9 & 2,82 & 811,9 \\
\hline $\mathrm{CV}(\%)$ & 4,51 & 12,32 & 16,86 & 15,30 & 6,15 & 22,37 \\
\hline
\end{tabular}

${ }^{(1)}$ Médias seguidas por letras iguais, na coluna, não diferem entre si pelo teste de Tukey, a 5\% de probabilidade. ${ }^{(2)}$ Variedade avaliada como não genitora. 
experimentos com menos de 30 tratamentos, podem ser classificados como medianos os CV entre 12,2 e $27,9 \%$.

A inclusão da interação tratamentos comuns x ensaios no resíduo não contribuiu muito para inflacionar o erro experimental, pois os $\mathrm{CV}$ dos experimentos das gerações $\mathrm{F}_{1}$ e $\mathrm{F}_{3}$ foram, respectivamente, de 20,9 e $23 \%$, muito próximos do valor $(22,4 \%)$ verificado para a análise conjunta, acima referida.

Na Tabela 2, estão relacionados: a produtividade média de grãos dos grupos genéticos das variedades genitoras, os cruzamentos na geração $\mathrm{F}_{1} \mathrm{e}$ cruzamentos na geração $\mathrm{F}_{3}$. A produtividade de grãos dos cruzamentos na geração $F_{3}$ é significativamente menor que a observada na $\mathrm{F}_{1}$, o que indica a ocorrência esperada de depressão por endogamia (Vencovsky \& Barriga, 1992). Na geração $F_{3}$, houve também menor variação entre os cruzamentos, revelada pelo menor coeficiente de variação genética para os tratamentos dentro de grupo. Efeitos diferenciais da heterose, nas várias combinações híbridas, contribuíram provavelmente para a maior variação genética em $F_{1}$. A forte presença de heterose, revelada pela maior produtividade da geração $\mathrm{F}_{1}$, em relação aos genitores, aponta para uma forte influência dos efeitos de dominância, na expressão do caráter produtividade de grãos das combinações híbridas (Oliveira et al., 2004, 2007).

Treze dos 45 cruzamentos resultaram em famílias $\mathrm{F}_{1}$ significativamente mais produtivas do que a média das suas respectivas variedades parentais. Sete desses cruzamentos que apresentaram heterose significativa envolveram uma ou as duas variedades mais produtivas, AL03 e PB13 (Tabela 3). Apesar de quatro cruzamentos terem se revelado significativamente menos produtivos do que seus genitores, em média,

Tabela 2. Produção de grãos dos grupos avaliados, probabilidade da estatística $\mathrm{F}$ em ausência de variação dentro do grupo $\left(\mathrm{H}_{0}\right)$ e coeficiente de variação genética $(\mathrm{CVg})$ quanto aos tratamentos dentro dos grupos: genitores, cruzamentos em $\mathrm{F}_{1}$ e cruzamentos $\mathrm{em}_{3} \mathrm{~F}^{(1)}$.

\begin{tabular}{lcrc}
\hline Grupo genético & $\begin{array}{c}\text { Produção de } \\
\text { grãos }\left(\mathrm{g} \mathrm{m}^{-2}\right)\end{array}$ & $\operatorname{Pr}>\mathrm{F}$ & $\mathrm{CVg}(\%)$ \\
\hline Genitores & $765,2 \mathrm{~b}$ & 0,0225 & 10,95 \\
Cruzamentos em $\mathrm{F}_{1}$ & $886,7 \mathrm{a}$ & $<0,0001$ & 23,40 \\
Cruzamentos em $\mathrm{F}_{3}$ & $737,9 \mathrm{~b}$ & 0,0061 & 13,01 \\
\hline
\end{tabular}

${ }^{(1)}$ Médias seguidas por letras iguais não apresentam diferenças significativas pelo teste de Tukey, a 5\% de probabilidade. as combinações foram positivamente heteróticas em $\mathrm{F}_{1}\left(\overline{\mathrm{h}}=121,5 \pm 37,6 \mathrm{~g} \mathrm{~m}^{-2}\right)$. Na geração $\mathrm{F}_{3}$, porém, apenas cinco cruzamentos apresentaram médias significativamente superiores às dos pais, o que mostra o efeito de heterose $\left(\mathrm{H}_{3}\right)$ positiva. Destacaram-se, nesse sentido, os cruzamentos 'PB04' x 'PB09', 'PB04' $\mathrm{x}$ 'PB10' e 'PB05' x 'PB10', tanto pelas estimativas de $\mathrm{H}_{3}$, como pelo desempenho médio dos parentais, que não diferiram significativamente dos genitores mais produtivos, 'AL03' e 'PB13'.

A Tabela 4 apresenta o desdobramento da soma de quadrados (SQ) de tratamentos (variedades genitoras + cruzamentos em $\mathrm{F}_{1}+$ cruzamentos em $\mathrm{F}_{3}$ ) em soma de quadrados dos efeitos do modelo dialélico utilizado. No presente trabalho, não há independência entre os componentes das fontes de variação e, portanto, as suas SQ não são aditivas. Por exemplo, o desdobramento das SQ de tratamentos em SQ de variedades genitoras e de heteroses, em $F_{1}$ e em $\mathrm{F}_{3}$, resultou em SQ parciais que, quando somadas, corresponderam a aproximadamente $58 \%$ da SQ de tratamentos. No entanto, o somatório das SQ da heterose em $F_{1}$ foi bastante inferior à $S Q$ de seus componentes. A razão dessas distorções resulta do fato de existir, na matriz de variância do vetor de soluções do modelo dialélico, vários casos de co-variações elevadas. Como exemplo, a correlação entre v e h, na geração $\mathrm{F}_{1}$, do genitor 'AL01' foi de $-0,67$.

As variedades genitoras não formaram um grupo homogêneo. A significância da variação associada aos efeitos de variedades genitoras e de heterose dos cruzamentos são evidências de divergência genética entre elas. A presença de variação, em razão da heterose média em $\mathrm{F}_{1}$, indica que os cruzamentos apresentaram vigor híbrido, quando considerados em conjunto (Gardner \& Heberhart, 1966). Na geração $F_{3}$, no entanto, a heterose média não foi significativa, o que explica porque os cruzamentos nessa geração, em conjunto, não diferiram da média dos pais (Tabela 2). A grande variação em conseqüência da heterose varietal, tanto em $\mathrm{F}_{1}$ quanto $\mathrm{em}_{3}$, indica que há diferenças entre as variedades genitoras quando estão em cruzamento entre si, nas duas gerações. Adicionalmente, a significância do quadrado médio associado à heterose específica foi maior na $F_{1}$ do que na $F_{3}$, o que indica que há variação entre as variedades quanto aos efeitos de dominância dos alelos, em locos contrastantes, e que por essa razão, a variação se reduz com a endogramia.

As estimativas dos parâmetros do modelo de análise dialélica empregado estão relacionadas na Tabela 5 . 
Os dois genitores mais produtivos, 'AL03' e 'PB13', apresentaram as maiores estimativas de efeito varietal, e o genitor menos produtivo, 'PB12', apresentou a estimativa mais negativa $\left(\mathrm{v}=-165,2 \mathrm{~g} \mathrm{~m}^{-2}\right)$. Ao mesmo tempo, as estimativas dos componentes da heterose são muito dependentes da geração de endogamia. Por exemplo, a estimativa da heterose média na geração $\mathrm{F}_{1}\left(\overline{\mathrm{h}}_{1}=121,5 \mathrm{~g} \mathrm{~m}^{-2}\right)$ correspondeu a $15,9 \%$ da média dos genitores (765,2 $\mathrm{g} \mathrm{m}^{-2}$, Tabela 2), enquanto na geração $\mathrm{F}_{3}$ a heterose média não foi significativa. A estimativa de $\bar{h}_{1}$ indicou bom vigor híbrido na geração $F_{1}$.

A heterose varietal de um genitor de dialelo é definida como a diferença entre a média das heteroses de todos os seus híbridos e a heterose média do dialelo, na mesma geração (Vencovsky \& Barriga, 1992). Apenas os genitores 'AL03' e 'PB11' tiveram uma estimativa de $\mathrm{h}_{1}$ (heterose varietal na geração $\mathrm{F}_{1}$ ) significativamente maior que zero, o que é uma indicação de que essas variedades apresentam maior divergência em relação ao grupo de genitores utilizados (Cruz \& Regazzi, 1994; Viana, 2007). Provavelmente, a heterose varietal da 'AL03' em $F_{1}$ resultou de efeitos de dominância, pois em $\mathrm{F}_{3}$ esse genitor apresentou heterose varietal negativa. Este resultado reduz a perspectiva de uso daquela variedade como genitora de linhagens elite. Inversamente, o genitor 'PB04' apresentou heterose varietal mediana em $\mathrm{F}_{1}$, mas sobressaiu-se na geração $\mathrm{F}_{3}$ quanto a este parâmetro. Isto indica que seus cruzamentos apresentaram, em média, menor depressão por endogamia e, portanto, o seu melhor desempenho deve advir de efeitos gênicos aditivos positivos, o que o torna um genitor promissor para o melhoramento de arroz-vermelho, quanto à maior produtividade de grãos.

A capacidade geral de combinação (g) de um genitor resulta de uma combinação linear de $\mathrm{v}$ e h (Gardner \& Heberhart, 1966; Geraldi \& Miranda Filho, 1988; Vencovsky \& Barriga, 1992), portanto, inclui o efeito de variedade e a heterose varietal. Os genitores que apresentaram as maiores estimativas de $\mathrm{g}$ foram 'AL03', 'PB13' e 'PB05', as três variedades mais produtivas. No outro extremo, 'AL01' e 'AL04' apresentaram as menores estimativas de $\mathrm{g}$, o que possivelmente se deve à menor divergência genética em relação ao conjunto de genitores utilizados (Cruz \& Regazzi, 1994).

A Tabela 6 apresenta as heteroses específicas dos cruzamentos dialélicos nas gerações $F_{1}$ e $F_{3}$. Maiores estimativas são esperadas em cruzamentos

Tabela 3. Estimativas de heterose $(H)$ dos cruzamentos nas gerações $F_{1}$ (acima da diagonal) e $F_{3}$ (abaixo da diagonal), em $g \mathrm{~m}^{-2}$.

\begin{tabular}{|c|c|c|c|c|c|c|c|c|c|c|}
\hline Genitor & AL01 & AL03 & AL04 & PB04 & PB05 & PB09 & PB10 & PB11 & PB12 & PB13 \\
\hline AL01 & & $-19,2$ & $-240,1^{*}$ & $-107,6$ & $-17,8$ & 26,0 & $-251,5^{*}$ & 169,7 & $-130,9$ & $-57,3$ \\
\hline AL03 & $-169,6$ & & 64,6 & $262,7^{*}$ & 150,8 & $303,5 *$ & 232,7 & 223,3 & $425,6^{* *}$ & $282,5^{*}$ \\
\hline AL04 & $-124,3$ & $-38,1$ & & 1,8 & $-50,1$ & 196,0 & $-125,4$ & $-78,2$ & $-243,8^{*}$ & $-345,2 * *$ \\
\hline PB04 & $-98,4$ & $-164,4$ & 167,6 & & 147,5 & 84,0 & $420,6 * *$ & 214,4 & 183,3 & $334,7 *$ \\
\hline PB05 & 34,1 & $-131,9$ & $-75,3$ & 14,9 & & $608,9 * *$ & $-185,4$ & $319,2 * *$ & 232,5 & 156,1 \\
\hline PB09 & 54,6 & $-142,3$ & $-192,9$ & $297,6^{*}$ & $-214,3$ & & $-132,1$ & 157,9 & 160,7 & 223,2 \\
\hline PB 10 & $-118,9$ & $-8,2$ & $-221,7$ & $246,3 *$ & $256,6^{*}$ & $-18,5$ & & $466,1 * *$ & $278,3^{*}$ & 207,5 \\
\hline PB11 & $-110,7$ & $-249,9 *$ & 73,2 & 79,0 & $-219,6$ & 152,0 & 169,6 & & $318,9 * *$ & $259,1^{*}$ \\
\hline PB12 & $-68,4$ & $-214,3$ & $-166,9$ & 139,0 & $352,8^{*}$ & $252,0^{*}$ & 2,9 & 37,9 & & $339,1 * *$ \\
\hline PB13 & $-207,1$ & $-175,2$ & $-178,8$ & $-126,3$ & $-124,9$ & 55,6 & $-40,2$ & $-163,0$ & 150,4 & \\
\hline
\end{tabular}

* e **Significativo pelo teste $\mathrm{t}$, a 5 e $1 \%$ de probabilidade, respectivamente.

Tabela 4. Decomposição não ortogonal da soma de quadrados de produção de grãos $\left(\mathrm{g} \mathrm{m}^{-2}\right)$, relativa a tratamentos em efeitos do modelo dialélico utilizado.

\begin{tabular}{|c|c|c|c|c|}
\hline Fonte de variação & Graus de liberdade & Soma de quadrados & Quadrado médio & Estatística F \\
\hline Tratamentos & 99 & 10.696 .314 & 108.044 & $3,27 * *$ \\
\hline Variedades & 9 & 656.860 & 72.984 & $2,21 * *$ \\
\hline Heterose em $\mathrm{F}_{1}$ & 45 & 3.134 .716 & 69.660 & $2,11 * *$ \\
\hline Heterose média em $F_{1}$ & 1 & 344.509 & 344.509 & $10,44 * *$ \\
\hline Heterose varietal em $\mathrm{F}_{1}$ & 9 & 1.597 .049 & 177.450 & $5,38 * *$ \\
\hline Heterose específica em $F_{1}$ & 35 & 2.677 .344 & 76.496 & $2,32 * *$ \\
\hline Heterose em $\mathrm{F}_{3}$ & 45 & 2.384 .444 & 52.988 & $1,61 * *$ \\
\hline Heterose média em $\mathrm{F}_{3}$ & 1 & 20.430 & 20.430 & $0,62^{\mathrm{ns}}$ \\
\hline Heterose varietal em $\mathrm{F}_{3}$ & 9 & 614.355 & 68.262 & $2,07 * *$ \\
\hline Heterose específica em $\mathrm{F}_{3}$ & 35 & 1.709 .850 & 48.853 & $1,48^{*}$ \\
\hline Resíduo & 208 & 6.864 .699 & 33.003 & - \\
\hline
\end{tabular}

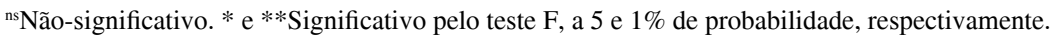


entre variedades mais divergentes quanto a genes que mostram efeitos de dominância (Cruz \& Regazzi, 1994). Esse é um parâmetro importante na definição das melhores combinações, em programas de obtenção de cultivares híbridas. Assim, esperase uma redução da heterose específica como fonte de variação entre cruzamentos com o avanço de gerações de endogamia. Oito cruzamentos apresentaram heterose específica significativa na geração $\mathrm{F}_{1}$, e quatro na geração $\mathrm{F}_{3}$. Esses resultados são concordantes com os testes de significância apresentados na Tabela 4 , em que se observa a tendência de perda de relevância da heterose específica como causa de variação entre os cruzamentos, com o avanço da endogamia.

Em termos gerais, nenhuma das variedades parentais avaliadas neste estudo reuniu todas as características ideais de um genitor para melhoramento, ou seja, alto desempenho per si e alta divergência em relação aos demais genótipos avaliados, cujos cruzamentos apresentem elevado potencial para seleção de linhagens elite. As variedades PB05 e PB10, apesar de não terem se destacado quanto a v e a $\mathrm{h}$, produziram cruzamento promissor, em razão da boa capacidade de combinação da primeira e da elevada estimativadeheterose específica em $\mathrm{F}_{3}$ do cruzamento entre ambas. Pode-se presumir que há boa capacidade específica de combinação (cec) entre essas duas variedades, pela íntima relação entre cec e heterose específica. $\mathrm{O}$ cruzamento entre 'AL03' e 'PB13', no entanto, não apresentou heterose específica significativa em F3, porém os dois genitores apresentam boa capacidade geral de combinação (g) e efeitos varietais (v) positivos e significativos, no que tange à produção de grãos. $\mathrm{O}$ cruzamento entre esses dois genitores deve, também, ser considerado promissor, por suas estimativas favoráveis de $\mathrm{v}$ e g, conseqüência direta dos efeitos aditivos, e da ausência de efeitos negativos significativos de heterose específica entre eles. Ambos os cruzamentos deverão permitir, inclusive, a seleção de linhagens de ciclo menos longo e de menor altura de planta, pois pelo menos um de seus genitores apresenta essas características.

Tabela 5. Estimativas e desvios-padrão dos efeitos de variedade (v), heterose varietal nas gerações $F_{1}\left(h_{1}\right)$ e $F_{3}\left(h_{3}\right)$, capacidade geral de combinação $(\mathrm{g})$ e heterose média dos cruzamentos $\left(\overline{\mathrm{h}}_{1}\right)$ entre dez variedades de arroz-vermelho, $\mathrm{em} \mathrm{g} \mathrm{m}^{-2(1)}$.

\begin{tabular}{|c|c|c|c|c|}
\hline Genitor & $\mathrm{V}$ & $\mathrm{h}_{1}$ & $\mathrm{~h}_{3}$ & $\mathrm{~g}$ \\
\hline AL01 & $-94,7 \pm 77,3 b c$ & $-215,3 * * \pm 53,7 \mathrm{~b}$ & $-70,4 \pm 53,7 \mathrm{~cd}$ & $-190,2 * * \pm 26,7 \mathrm{c}$ \\
\hline AL03 & $170,4^{*} \pm 70,7 \mathrm{a}$ & $104,1^{*} \pm 50,8 \mathrm{a}$ & $-131,0 * \pm 54,1 \mathrm{~d}$ & $71,8 * * \pm 27,2 \mathrm{a}$ \\
\hline AL04 & $31,0 \pm 70,7 \mathrm{abc}$ & $-239,2 * * \pm 50,0 \mathrm{~b}$ & $-63,9 \pm 58,5 \mathrm{bcd}$ & $-136,1 * * \pm 29,2 \mathrm{c}$ \\
\hline PB04 & $-78,5 \pm 70,7 b c$ & $56,0 \pm 49,9 a$ & $100,1 * \pm 50,9 \mathrm{a}$ & $38,8 \pm 25,4 \mathrm{ab}$ \\
\hline PB05 & $78,6 \pm 77,3 \mathrm{abc}$ & $33,6 \pm 52,5 \mathrm{a}$ & $17,2 \pm 54,5 \mathrm{abcd}$ & $64,7 * \pm 26,1 \mathrm{ab}$ \\
\hline PB09 & $-33,4 \pm 77,3 a b c$ & $66,9 \pm 52,7 \mathrm{a}$ & $61,2 \pm 56,7 \mathrm{abc}$ & $47,3 \pm 27,4 \mathrm{ab}$ \\
\hline PB10 & $-1,8 \pm 70,7 \mathrm{abc}$ & $-22,8 \pm 49,9 a$ & $64,2 \pm 54,1 \mathrm{abc}$ & $19,8 \pm 27,0 \mathrm{ab}$ \\
\hline PB11 & $-71,9 \pm 70,7 \mathrm{bc}$ & $119,6 * \pm 49,9 \mathrm{a}$ & $1,8 \pm 53,4 \mathrm{abcd}$ & $24,8 \pm 26,7 \mathrm{ab}$ \\
\hline PB12 & $-165,2 * \pm 70,7 \mathrm{c}$ & $58,8 \pm 50,0 \mathrm{a}$ & $91,4 \pm 53,9 \mathrm{ab}$ & $-7,5 \pm 27,0 b$ \\
\hline PB13 & $165,4 *_{ \pm} 70,7 \mathrm{a}$ & $38,3 \pm 50,0 \mathrm{a}$ & $-70,5 \pm 52,9 \mathrm{~cd}$ & $66,6 * \pm 26,5 \mathrm{ab}$ \\
\hline Heterose média $(\overline{\mathrm{h}})$ & - & $121,5^{* *} \pm 37,6$ & $-27,3 \pm 34,7$ & - \\
\hline
\end{tabular}

${ }^{(1)}$ Estimativas seguidas por letras iguais não diferem entre si pelo teste t, a $5 \%$ de probabilidade. * e * Significativo pelo teste t, a 5 e $1 \%$ de probabilidade, respectivamente.

Tabela 6. Heterose específica (s) dos cruzamentos entre os dez genitores de arroz-vermelho, nas gerações $F_{1}$ (acima da diagonal) e $\mathrm{F}_{3}$ (abaixo da diagonal), em $\mathrm{g} \mathrm{m}^{-2}$.

\begin{tabular}{|c|c|c|c|c|c|c|c|c|c|c|}
\hline Genitor & AL01 & AL03 & AL04 & PB04 & PB05 & PB09 & PB10 & PB11 & PB12 & PB13 \\
\hline AL01 & - & $-29,6$ & 92,9 & $-69,8$ & 42,4 & 52,9 & $-134,9$ & 143,8 & $-95,9$ & $-1,8$ \\
\hline AL03 & 59,1 & - & 78,2 & $-18,9$ & $-108,4$ & 11,0 & 29,9 & $-122,0$ & 141,1 & 18,5 \\
\hline AL04 & 37,3 & 184,2 & - & 63,5 & 34,1 & $246,9 * *$ & 15,1 & $-80,1$ & $-184,8 *$ & $-265,8 * *$ \\
\hline PB04 & $-100,9$ & $-106,1$ & 158,7 & - & $-63,6$ & $-160,3$ & $265,9 * *$ & $-82,7$ & $-53,0$ & 118,9 \\
\hline PB05 & 114,5 & 9,2 & $-1,3$ & $-75,2$ & - & $387,0 * *$ & $-317,6^{* *}$ & 44,5 & 18,7 & $-37,2$ \\
\hline PB09 & 91,1 & $-45,1$ & $-162,8$ & 163,6 & $-265,5^{* *}$ & - & $-297,6 * *$ & $-150,0$ & $-86,4$ & $-3,4$ \\
\hline PB10 & $-85,4$ & 86,0 & $-194,6$ & 109,2 & $202,4^{*}$ & $-116,6$ & - & $247,8 * *$ & 120,8 & 70,5 \\
\hline PB11 & $-14,8$ & $-93,4$ & 162,7 & 4,4 & $-211,3 *$ & 116,4 & 130,9 & - & 19,0 & $-20,3$ \\
\hline PB12 & $-62,1$ & $-147,4$ & $-167,0$ & $-25,2$ & $271,4^{*}$ & 126,8 & $-125,3$ & $-28,0$ & - & 120,6 \\
\hline PB13 & $-38,9$ & 53,6 & $-17,1$ & $-128,6$ & $-44,3$ & 92,2 & $-6,6$ & $-67,0$ & 156,8 & - \\
\hline
\end{tabular}

* e **Significativo pelo teste $\mathrm{t}$, a 5 e $1 \%$ de probabilidade, respectivamente. 


\section{Conclusões}

1. Há diferenças entre as variedades parentais de arroz-vermelho relativas a produtividade de grãos, duração do ciclo vegetativo, altura de planta, número de panículas por planta, número de espiguetas por panícula e massa de grãos.

2. Na geração $\mathrm{F}_{3}$, a heterose média é nula.

3. Os maiores efeitos quanto à capacidade geral de combinação são apresentados pelas variedades AL 03, PB 05 e PB13.

4. Os cruzamentos 'PB05/PB10' e 'AL03/PB13' são promissores como fontes de novas linhagens de arrozvermelho.

\section{Referências}

AREIAS, R.G. de B.M.; PAIVA, D.M. de; SOUZA, S.R.; FERNANDES, M.S. Similaridade genética de variedades crioulas de arroz, em função da morfologia, marcadores RAPD e acúmulo de proteína nos grãos. Bragantia, v.65, p.19-28, 2006.

COSTA, N.H. de A.D.; SERAPHIM, J.C.; ZIMMERMANN, F.J.P. Novo método de classificação de coeficientes de variação para a cultura do arroz de terras altas. Pesquisa Agropecuária Brasileira, v.37, p.243-249, 2002.

CRUZ, C.D.; REGAZZI, A.J. Modelos biométricos aplicados ao melhoramento genético. Viçosa: UFV, 1994. 389p.

GARDNER, C.O.; EBERHART, S.A. Analysis and interpretation of the variety cross diallel and related populations. Biometrics, v.22, p.439-452, 1966.

GERALDI, I.O.; MIRANDA FILHO, J.B. Adapted models for the analysis of combining ability of varieties in partial diallel crosses. Revista Brasileira de Genética, v.11, p.419-430, 1988.

GRAVOIS, K.A.; McNEW, R.W. Combining ability and heterosis in U.S. southern long-grain rice. Crop Science, v.33, p.83-86, 2003.

GRIFFING, B. Concept of general and specific combining ability in relation to diallel crossing systems. Australian Journal of Biological Sciences, v.9, p.463-493, 1956.

KUREK, A.J.; CARVALHO, F.I.F. de; ASSMANN, I.C.; CRUZ, P.J. Capacidade combinatória como critério de eficiência na seleção de genitores em feijoeiro. Pesquisa Agropecuária Brasileira, v.36, p.645-651, 2001.

OLIVEIRA, J.P. de; CHAVES, L.J.; DUARTE, J.B.; BRASIL, E.M.; FERREIRA JÚNIOR, L.T.; RIBEIRO, K. de O. Teor de proteína no grão em populações de milho de alta qualidade protéica e seus cruzamentos. Pesquisa Agropecuária Tropical, v.34, p.45-51, 2004.
OLIVEIRA, J.P. de; CHAVES, L.J.; DUARTE, J.B.; BRASIL, E.M.; RIBEIRO, K. de O. Qualidade física do grão em populações de milho de alta qualidade protéica e seus cruzamentos. Pesquisa Agropecuária Tropical, v.37, p.233-241, 2007.

PASSOS, A.R.; SILVA, S.A.; CRUZ, P.J.; ROCHA, M. de M.; CRUZ, E.A. de O.; ROCHA, M.A.C. da; BAHIA, H.F.; SALDANHA, R.B. Divergência genética em feijão-caupi. Bragantia, v.66, p.579-586, 2007.

PEREIRA, J.A. O arroz-vermelho cultivado no Brasil. Teresina: Embrapa Meio-Norte, 2004. 90p.

PEREIRA, J.A. Cultura do arroz no Brasil: subsídios para a sua história. Teresina: Embrapa Meio-Norte, 2002. 226p.

PEREIRA, J.A.; BASSINELLO, P.Z.; FONSECA, J.R.; RIBEIRO, V.Q. Potencial genético de rendimento e propriedades culinárias do arroz-vermelho cultivado. Revista Caatinga, v.20, p.43-48, 2007.

PINHEIRO, B. da S. Características morfofisiológicas da planta relacionadas à produtividade. In: SANTOS, A.B. dos; STONE, L.F.; VIEIRA, N.R. de A. (Ed.). A cultura do arroz no Brasil. Santo Antônio de Goiás: Embrapa Arroz e Feijão, 2006. p.209-256.

RODRIGUES, L.S.; ANTUNES, I.F.; TEIXEIRA, M.G.; SILVA, J.B. da. Divergência genética entre cultivares locais e cultivares melhoradas de feijão. Pesquisa Agropecuária Brasileira, v.37, p.1275-1284, 2002.

SAS INSTITUTE. SAS/STAT software: syntax: version 6. Cary: SAS Institute, 1993. 151p.

SEARLE, S.R. Linear models. New York: John Wiley \& Sons, 1971. 532p.

SILVA, S.A.G. e; MORAIS, O.P. de; RAVA, C.A.; COSTA, J.G.C. da. Método generalizado de análise de dialelos desbalanceados. Pesquisa Agropecuária Brasileira, v.35, p.1999-2005, 2000.

SWEENEY, M.T.; THOMSON, M.J.; PFEIL, B.E.; McCOUCH, S. Caught red-handed: $R c$ encodes a basic helix-loop-helix protein conditioning red pericarp in rice. The Plant Cell, v.18, p.283-294, 2006.

VEIGA, R.D.; FERREIRA, D.F.; RAMALHO, M.A.P. Eficiência dos dialelos circulantes na escolha de genitores. Pesquisa Agropecuária Brasileira, v.35, p.1395-1406, 2000.

VENCOVSKY, R.; BARRIGA, P. Genética biométrica no fitomelhoramento. Ribeirão Preto: Sociedade Brasileira de Genética, 1992. 496p.

VIANA, J.M.S. Heterosis and combining ability analyses from the partial diallel. Bragantia, v.66, p.641-647, 2007.

VIANA, J.M.S. The parametric restrictions of the Gardner and Eberhart diallel analysis model: heterosis analysis. Genetics and Molecular Biology, v.23, p. 877-881, 2000.

ZIMMERMANN, F.J.P. Estatística aplicada à pesquisa agrícola. Santo Antônio de Goiás: Embrapa Arroz e Feijão, 2004. 402p.

Recebido em 28 de fevereiro de 2008 e aprovado em 29 de agosto de 2008 